\title{
SPERM MORPHOLOGICAL ASSESSMENTS OF FRIESIAN HOLSTEIN BULL SEMEN COLLECTED FROM THREE ARTIFICIAL INSEMINATION CENTERS IN INDONESIA
}

\author{
B. Purwantara ${ }^{1}$, R. I. Arifiantini ${ }^{1}$ and M. Riyadhi ${ }^{2}$ \\ ${ }^{1}$ Department of Clinic, Reproduction, and Pathology, Faculty of Veterinary Medicine, \\ Bogor Agricultural University, Darmaga Campus, Bogor 16680 - Indonesia \\ ${ }^{2}$ Study Program of Animal Production, Faculty of Agriculture, \\ Lambung Mangkurat University, \\ Jl. A. Yani km 36. Banjarbaru, South Kalimantan - Indonesia \\ Corresponding E-mail : b.purwantara@biotrop.org
}

Received November 19, 2009; Accepted March 20, 2010

\begin{abstract}
Morphologically abnormal sperm in semen has been associated with the sub fertility and sterility for many years. This study assessed the sperm morphology of Friesian Holstein bull semen which was collected from three Artificial Insemination centers in Indonesia. Total of 22 bulls were used in this study; an ejaculate from each bull was examined. Three to four glass slides were prepared for each bull sample; a drop of semen was placed on each glass slide, smeared, and air-dried. The smeared samples were stained with carbolfuchsin-eosin (Williams stain). Morphological abnormality types were recorded from total of 500 spermatozoa. Results demonstrated that all 22 bulls had low sperm abnormality $(<10 \%)$. Pearshaped was the most frequently type of sperm abnormality found in the samples $(0.81 \pm 0.93 \%)$; while detached head was the lowest $(0.01 \pm 0.04 \%)$.

Keywords : Artificial Insemination centers, FH, sperm morphology
\end{abstract}

\section{INTRODUCTION}

Friesian Holstein (FH) dairy cattle are commonly raised and breed in Indonesia. The FH dairy cattle are currently bred by artificial insemination using frozen semen which are collected and processed at Artificial Insemination Centers (AIC) and distributed in different regions in Indonesia. Bulls served as donors in the production of highly qualified frozen semen at AIC to be distributed to nationally in Indonesia have to pass a performance testing.

One of the methods used to predict the potential fertility of a bull is breeding soundness evaluation (BSE) (Hopkins and Spitzer, 1997) or bull breeding soundness evaluation (BBSE) (Alexander, 2008). Worldwide, BSE has been used to assess the breeding potential of bulls (Godfrey and Dodson, 2005; Makhzoomi et al., 2007 and Hoflack et al., 2006), boars (Shipley, 1999) and stallions (Griffin, 2000).

Breeding soundness evaluation is a practical, relatively inexpensive, and very useful method in breeding program (Alexander, 2008). Society for Theriogenology (SFT) currently use guidelines adapted from 1993, BBSE standard which require a bull to pass the minimum standards of four categories including general reproductive organs, scrotal circumference index based on its age, sperm motility, and sperm morphology.

Breeding soundness evaluation has been well applied in artificial insemination centers in Indonesia, however, semen analysis is limited to sperm concentration and motility (sperm movement), while sperm morphology (abnormalities and normal structure) has not much been performed. Information on sperm morphology in Indonesia is limited. Sperm morphological assessments were reported in Bali bulls (Arifiantini et al., 2006) and water buffaloes (Arifiantini and Ferdian, 2006).

Ax et al. (2000) classified spermatozoa abnormality into three groups: primary abnormalities (those affecting the sperm head and acrosome), secondary abnormalities (those affecting the midpiece cytoplasmic droplet), and tertiary abnormalities (tail damage). In advanced countries such as United States, Sweden, and Netherlands, sperm morphological abnormality assessment is one of the important factors in the 
production of liquid and frozen semen (Arifiantini et al., 2006); therefore, there are certain standards for a bull's semen that is allowed to use in artificial insemination program.

The main focus of this study is the primary sperm abnormalities which commonly affect the head; these abnormalities are extremely important because the sperm's head contain nucleus which bears genetic material and acrosomal enzyme for fertilization. The secondary and tertiary sperm abnormalities which commonly occur in the tails are easily detected during sperm motility evaluation; sperm with tail abnormalities such as coil and bent tails commonly do not demonstrate a progressive movement. Primary sperm abnormalities are difficult to detect; sperm with narrow-head and microcephalus tend to move more progressively due to their more slender structure compare to normal spermatozoa.

This study aimed to evaluate the sperm morphology (normal structure and abnormalities), particularly primary sperm abnormalities in $\mathrm{FH}$ bull semen at three AI centers in Indonesia.

\section{MATERIALS AND METHODS}

Friesian Holstein bull semen samples were collected from three AI centers. Staining and observation of smeared semen samples were performed at Reproductive Rehabilitation Unit Laboratory, Faculty of Veterinary Medicine, Bogor Agricultural University. Sample collections, staining, and observations were done from July to December 2009.

\section{Semen sample Collections}

Smeared semen samples were collected by technicians at each AI centers and delivered to the laboratory in Bogor. Semen samples were collected according to the standard protocol: a drop of semen was placed on a glass slide, mixed by four drops of physiologic saline and homogenized by using a stick; thin smears were then made on 3-4 different glass slides. Smeared semen samples were air dried, coded according to the bull ID, and sent to the laboratory.

Smeared samples were stained with carbolfuchsin-eosin according to the method described by Williams in 1920 and modified by Lagerlof in 1934 (Kavak et al., 2004). Steps of Williams staining protocol were as follow. The air-dried, fresh semen thin smeared samples from AI centers/stations were fixed in flame, washed with absolute alcohol for 4 minutes, and air dried.
Then, the smears were treated with $0.5 \%$ chloramin solution for 2 minutes until the mucous had disappeared and the smears looked fairly clear. The smears were washed in distilled water, rinsed in 95\% alcohol, and stained with Williams solution for 8-10 minutes. Finally, the smears were washed in running water and allowed to dry.

Sperm morphology was evaluated using a light microscope (Olympus $\mathrm{CH} 20$ ) at 400x magnification. Five hundreds of spermatozoa were evaluated on each smear, focusing on the shape of sperm's heads. All types of primary sperm abnormality were recorded, classified, and documented. The classification of primary sperm abnormalities was based on the findings during the microscopic evaluation.

\section{Data analysis}

Friesian Holstein bull sperm morphology data and morphological variations of sperm between the AI centers were presented in mean \pm standard deviation (SD) which was calculated using Minitab software version 14.0.

\section{RESULTS AND DISCUSSION}

Sperm morphology can be evaluated using a light microscope or a phase contrast microscope; this depends on the type of staining used. In this study, semen samples were collected from 14 out of $15 \mathrm{AI}$ centers officially registered at Indonesian Directorate General of Livestock; and only three AI centers delivered FH bull semen samples with the total of 22 bulls.

Based on the sample origin, semen samples collected from B AI center tended to have higher primary sperm abnormality rate $(8,40 \%)$ than those collected from A AI center $(1,71 \%)$ and $\mathrm{C}$ AI center $(1,00 \%)$ (Figure 1$)$. The differences on sperm abnormality rates between AI centers were associated with sample variations in each AI center. In addition, the high primary sperm abnormality rate in B AI center might be caused by the differences of climate, environment, and management.

The most frequent type of primary sperm abnormality found in this study was pearshaped $(0.81 \pm 0.93 \%)$, while the least was detached head $(0.01 \pm 0.04 \%)$ (Table 1$)$. These primary sperm abnormalities were believed to be genetic in origin (Barth and Oko, 1989). Pearshaped or pyriform spermatozoa have the acrosomal (anterior) region full of chromatin or enlarged, while the postacrosomal (posterior) region is 


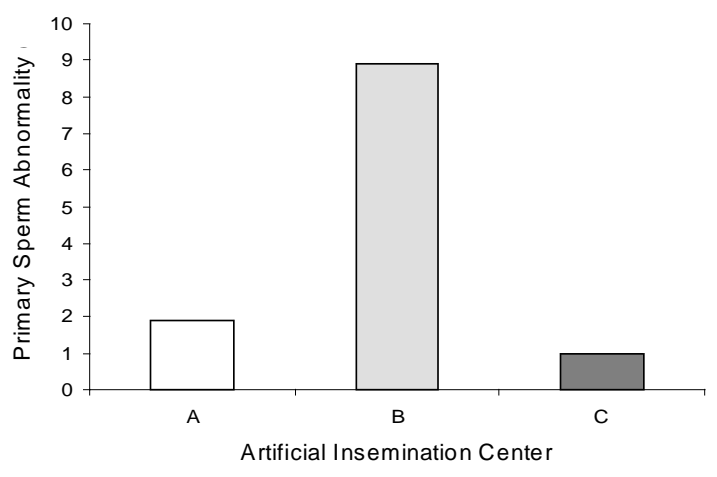

Figure 1. Sperm abnormality level in the three Artificial insemination centre

Tabel 1 . The Percentage of sperm abnormality in FH bull

\begin{tabular}{ll}
\hline \multicolumn{1}{c}{ Abnormality } & Means \pm SD \\
\hline Pearshaped & $0.81 \pm 0.93^{\mathrm{a}}$ \\
Narrow at the base & $0.29 \pm 0.66^{\mathrm{bc}}$ \\
Narrow & $0.42 \pm 0.66^{\mathrm{b}}$ \\
Abnormal contour & $0.19 \pm 0.57^{\mathrm{bc}}$ \\
Underdeveloped & $0.16 \pm 0.55^{\mathrm{bc}}$ \\
Round head & $0.04 \pm 0.08^{\mathrm{c}}$ \\
Macrocephalus & $0.06 \pm 0.11^{\mathrm{c}}$ \\
Microcephalus & $0.15 \pm 0.56^{\mathrm{bc}}$ \\
Double head & $0.03 \pm 0.09^{\mathrm{c}}$ \\
Abaxial & $0.13 \pm 0.35^{\mathrm{bc}}$ \\
Knnobbed acrosome defec & $0.17 \pm 0.20^{\mathrm{bc}}$ \\
Detached head & $0.01 \pm 0.04^{\mathrm{c}}$ \\
Diadem & $0.14 \pm 0.33^{\mathrm{bc}}$ \\
\hline
\end{tabular}

narrow and slightly elongated, with a distinct margin between the anterior and posterior regions.

Pearshaped or pyriform spermatozoa had their acrosomal (anterior) regions full of chromatin and rounded, while the postacrosomal region was narrow and slightly elongated, with a distinct margin between the anterior and posterior regions. Detached head occurred when the sperm head was separated from the tail. In this study, the incidence of detached head was $0.02 \pm 0.09 \%$. Detached head spermatozoa had the anterior region separated from the posterior; this type of abnormality is usually found in small numbers (less than 10\%) and is commonly associated with testicular hypoplasia. The high incidence of detached head may indicate a hereditary trait (Barth and Oko, 1989).
Several primary sperm abnormalities by genetic defects are knobbed acrosome defect and round headed; several abnormalities on the tail such as midpiece defect may be hereditary (Chenoweth, 2005). Midpiece defect is potentially dangerous because it affects the location of mitochondria, which converts ATP and ADP into energy for sperm's tail activity.

In this study, almost all types of primary sperm abnormality such as narrow at the base, narrow, abnormal contour, and others were found in different rates. Several types of the abnormalities are presented in Figure 2.

Sperm abnormality rate according to the Indonesian National Standard (INS) is $20 \%$; this rate includes the primary and secondary sperm abnormalities. This current study focused on the primary sperm abnormalities; this was based on the consideration that secondary sperm abnormalities affecting the tail could be selfselected during sperm motility examination. Spermatozoa with tail abnormalities, such as coiled or bent tails automatically do not show a progressive movement. Secondary sperm abnormalities are usually due to the environmental factors and are relatively easy to fix. On the other hand, primary sperm abnormalities affecting the head cannot be detected during sperm motility evaluation; spermatozoa with microcephalus, narrow head, or narrow at the base may have a more progressive movement than normal spermatozoa because of their more slender shape. Some primary sperm abnormalities are genetics in origin and hereditary.

A raised question will be "what is the acceptable primary sperm abnormality percentage in Indonesia?". The maximum acceptable sperm abnormality rate in semen to be processed into good frozen semen was not explicitly mentioned in 2005 INS. In reference to the INS standard which allows a maximum of $20 \%$ sperm abnormality rate including both primary and secondary abnormalities, it is expected that the primary sperm abnormality rate does not exceed $10 \%$. In this study, we classified the primary sperm abnormality rates were classified into low $(<5 \%)$, moderate $(5.1-10 \%)$, high $(10.1-15 \%)$, and very high $(>15 \%)$.

The FH bull primary sperm abnormality rate in this study was generally low, only $2.72 \pm 0.4 \%$. During the evaluation of total $22 \mathrm{FH}$ bull semen samples, there was a sample presenting a very high primary sperm abnormality rate $(18.2 \%)$; if 


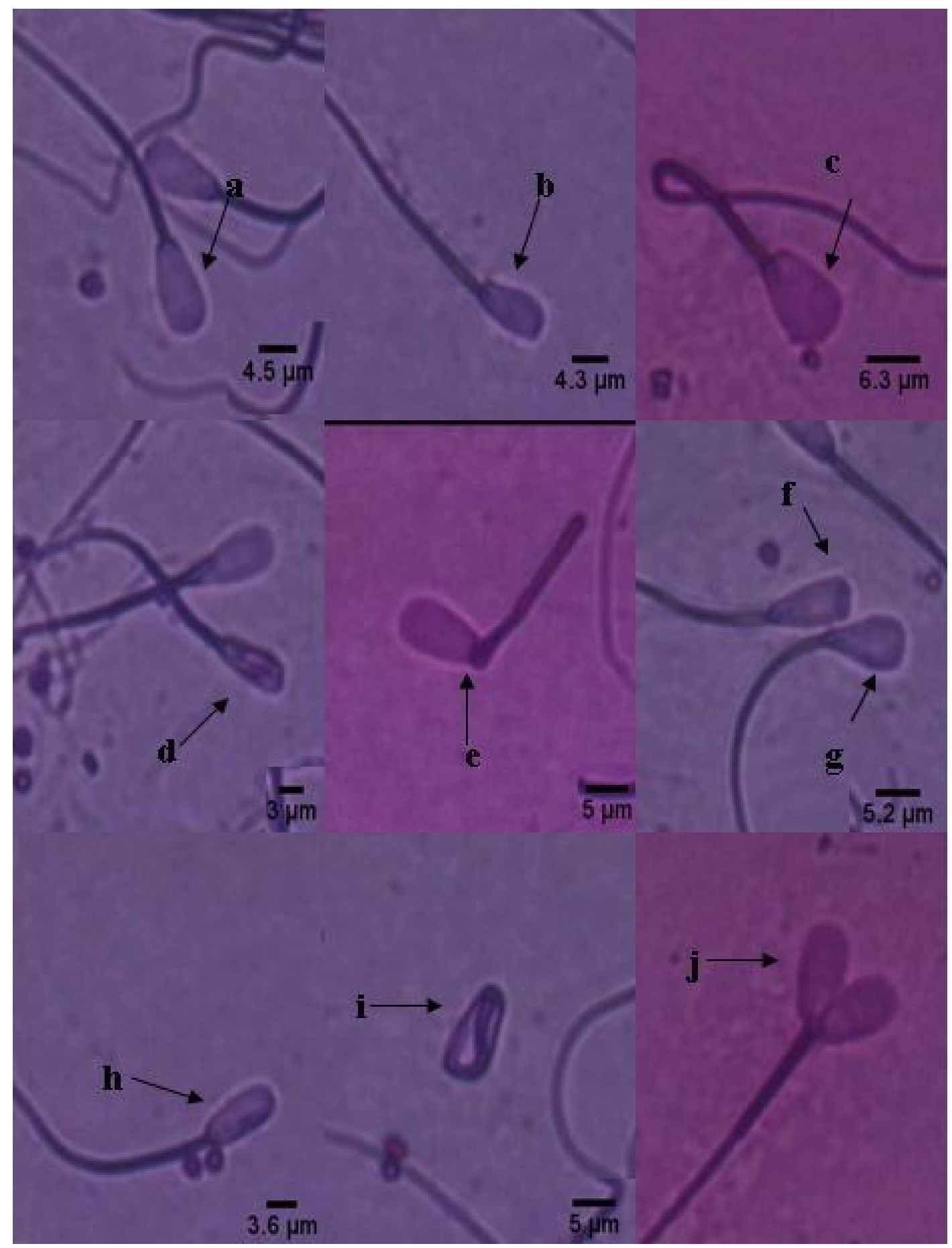

Figure 2. Sperm abnormality (Williams stains 1000x magnification)

a) normal sperm, b) Abaxial, c) Macrocephalus, d) Microcephalus,

e) Detached head, f) Abnormal contour, g) Pearshape, h) narrow

i) Undeveloped, j) Double head.

this sample had presented a 5\% secondary sperm abnormality rate, then the total abnormalities would be $23.2 \%$, which made it inappropriate to be processed into frozen semen. Based on this result, it is recommended to have the semen evaluated individually and not in random, thus,
FH bull semen samples presenting a high sperm abnormality rate will not be processed into frozen semen.

Generally, the sperm morphology in semen samples collected from the three AI centers was adequate; this fact was consistent with Balls and 
Peters (2004) statement that the sperm abnormality rate was considered important only when it occurred at $17 \%$ or within the range of 18 to 20\% (Barth and Oko, 1989). Ax et al. (2000) stated that semen presenting more than $20 \%$ sperm abnormality rate may demonstrate a decline in fertilizing potential. A bull will not have a high fertilizing capacity if the semen has presented high percentage of sperm abnormality because spermatozoa with abnormal morphology cannot fertilize oocyst (Sader, 2004).

\section{CONCLUSION}

FH bull sperm morphological abnormality rate in samples collected from three AI center in Indonesia was in normal range, which was between 1.00 to $8.40 \%$. The most frequent type of primary sperm abnormality was pearshaped or pyriform, while the lowest was detached head. Sperm morphological abnormality rates in samples collected from B AI center tended to be higher than samples collected from the other $2 \mathrm{AI}$ centers.

\section{ACKNOWLEDGMENT}

This study was supported by Directorate of Higher Education competency grant number 219/SP2H/PP/DP2M/V/2009 to Iis Arifiantini. We acknowledge all participated AI centers to sending fresh semen samples for the study materials.

\section{REFERENCES}

Alexander, J.H. 2008. Bull breeding soundness evaluation: A practitioner's perspective. Theriogenology 70: 469-472.

Arifiantini, R.I. and F. Ferdian. 2006. Tinjauan Aspek Morfologi dan Morfometri Spermatozoa Kerbau Rawa (Bubalus bubalis) yang Dikoleksi dengan Teknik Masase. Jurnal Veteriner. 7(2): 83-91

Arifiantini, R.I, T. Wresdiyati and E.F. Retnani. 2006. Pengujian morfologi spermatozoa sapi Bali (Bos sondaicus) menggunakan pewarnaan "Williams". Jurnal Pengembangan Peternakan Tropis (JPPT). 31(2):105-110

Ax, R.L, M.R. Dally, B.A. Didion, R.W. Lenz, C.C. Love, D.D. Varner, B. Hafez and M.E. Bellin. 2000. Semen Evaluation. In : Hafez ESE and B. Hafez Editor. Reproduction in Farm Animal. $7^{\text {th }}$ ed . USA: Lippincot Wiliams and Wilkins

Ball, P.J.H. and A.R. Peters. 2004. Reproduction in Cattle. Ed ke-3. UK: Blackwell Publishing.

Barth, A.D and R.J. Oko. 1989. Abnormal morphology of bovine spermatozoa. Iowa: Iowa State University Press.

Chenoweth, PJ. 2005. Genetic sperm defect. Theriogenology 64:457-468

Godfrey, R.W. and R.E. Dodson. 2005. Breeding soundness evaluations of Senepol bulls in the US Virgin Islands. Theriogenology 63:831840.

Griffin, P. 2000. The breeding soundness examination in the stallion J. Equine Vet. Sci. 20:168-171

Hoflack, G., A. Van Soom, D. Maes, A. De Kruif, G. Opsomer and L. Duchateau. 2006. Breeding soundness and libido examination of Belgian Blue and Holstein Friesian artificial insemination bulls in Belgium and The Netherlands. Theriogenology 66:207216.

Hopkins, F.M. and J.C. Spitzer 1997. The new society for theriogenology breeding soundness evaluation system. Bull infertility 13:283-293.

Kavak, A, N. Lundeheim, M. Aidnik and S. Einarsson. 2004. Sperm morphology in Estonian and Tori breed stallions. Act.Vet. Scan. 45:11-18.

Makhzoomi, A, N. Lundeheim, M. Haard, and H. Rodriguez-Martinez. 2007. Sperm morphology and fertility of progeny-tested AI Swedish dairy bull. J. Anim. Vet. Advances 8: 975-980.

Shipley, C.F. 1999. Breeding soundness examination of the boar. Swine Health Prod. 7: 117-120. 